DOI: https://doi.org/10.47405/aswj.v6i5.182

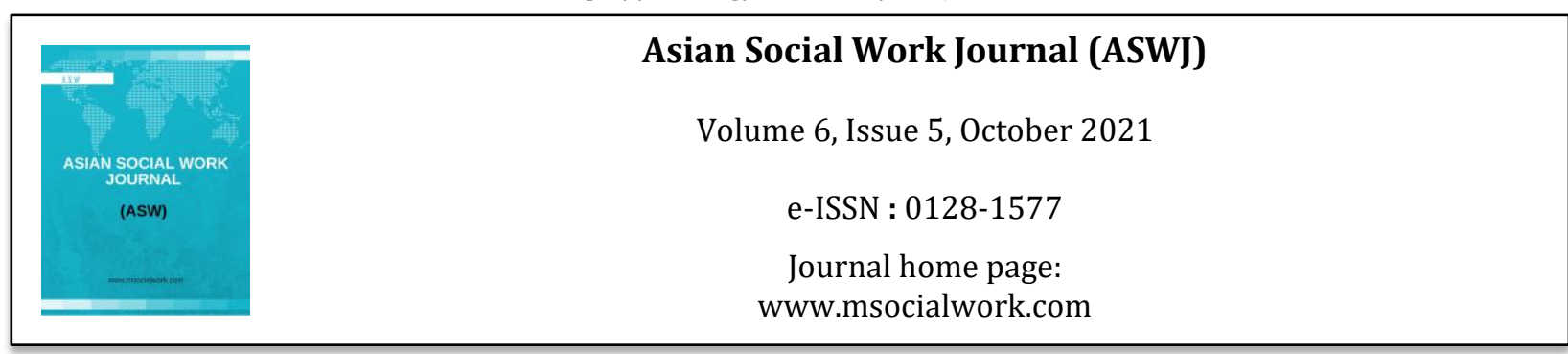

\title{
Applying Anti Oppressive, Empowerment, and Strengths Based Approaches to Social Work Practice with Hmong Clients
}

\author{
Serge C Lee ${ }^{1}$, Cindy Vang², Jenny Chang ${ }^{3}$, Pa Der Vang ${ }^{4}$ \\ ${ }^{1}$ California State University, Sacramento, United States \\ 2University of Minnesota, Twin Cities, United States \\ ${ }^{3}$ Southern New Hampshire University, United States \\ ${ }^{4}$ St. Catherine University, United States \\ Correspondence: Serge C Lee (lees@csus.edu)
}

\begin{abstract}
This conceptual article discusses social work practice with Hmong Americans using a framework that embraces anti-oppressive practice, empowerment and strengths-based approaches. Specifically, the Hmong kinship social construct of kwv tij neej tsa (pronounced: ku tee ning ja) is used to elaborate on the importance of upholding family relationships that transcends the worker-client relationship. Social workers are encouraged to empower Hmong to seek and ask for resources that support their collective value of connection to family and group identity, which is a strength that contributes to resilience and buffers against historically oppressive practices and systems.
\end{abstract}

Keywords: social work practice with Hmong, Hmong culture, anti-oppressive framework, strength based, empowerment

\section{Introduction}

The Council on Social Work Education (CSWE) mandates that cultural competence and cultural humility must be pedagogically imbedded within accredited social work programs. And accredited programs must develop their educational policy and accreditation standards to include dynamic and salient applications of diversity, equity, and social justice. Thus, contemporary social work practice must draw on strength frameworks that honor clients' cultural values, eliminates oppressive practices, and achieves equal access to resources for clients.

The anti-oppressive framework, empowerment and strengths-based approaches are recommended for social work practice with members of the Hmong community (Dewees, 2001; Palikas, 2010; Danso, 2018; Daniel, 2008; Dominelli \& Campling, 2002; Wilson \& Beresford, 2000). A major aim of this paper is not to demonstrate that the anti-oppressive framework, empowerment and strengths-based approaches have been successfully implemented with Hmong clients but rather to encourage social workers to intentionally consider using these three approaches in order to develop mindfulness in social work practice, prevent perpetuation of oppressive practices, empower clients to ask for what they need, and to recognize the inherent strengths that exist within clients' cultural milieu. 


\section{Background of Hmong Americans}

When the U.S. withdrew its military forces from Southeast Asia in 1975, the communist Pathet Lao came to power in Laos and one of its goals was to eradicate the Hmong in Laos (Hamilton-Merritt, 1993; Sommer, 2014). During this time, over 30,000 Hmong lives were lost (Hmong Peace Task Force Committee, 2007), resulting in a mass migration of many Hmong out of Laos to refugee camps located throughout northern Thailand. A majority of Hmong refugees from Thai refugee camps eventually resettled in the U.S. (Lee G, 2007; Lee M, 2015; McGrew, 2019; Yang; 2017).

Based on data available through the Pew Research Center, in 2020, there were 327,000 Hmong in the U.S. Currently the Twin Cities Metropolitan area has the highest Hmong population at over 81,000. The second and third most populated cities in the U.S. were Fresno, CA and Sacramento, CA. The median age of Hmong Americans is 25 with $66 \%$ of them being U.S. born and $34 \%$ reported as foreign born, with $81 \%$ of foreign-born individuals reported being naturalized citizens. About $64 \%$ of Hmong are employed with an annual median income of $\$ 68,000$. Approximately $15 \%$ of Hmong continue to live in poverty and $61 \%$ own their own home.

While Hmong have experienced many gains over the last 46 years, many continue to be underemployed, under educated, live in poverty, and face overt and covert discrimination and violence due to racism and xenophobia. Hmong face challenges such as severely unaddressed and untreated behavioral health issues (Lee \& Chang, 2012; Vang et al., 2020; Vang \& Bogenschutz, 2011), increasing chronic health conditions (Chen et al., 2013; Fang \& Steward, 2018), barriers to adaptation (i.e., gender role conflicts) (Thor, 2020), and an array of diminished social support, poor economic well-being, and educational disparities (Pew Research Center, 2020). Hmong also vary in terms of their acculturation to U.S. society. While some Hmong retain old traditions, others have shed Hmong traditions in favor of Western values and practices, and children born in the U.S. primarily lack deep cultural knowledge.

Many Hmong Americans have become more socially, politically, educationally, and economically competitive and efficient (Lee, 2020). For example, many Hmong are now employed in roles within major public and private sectors of the U.S. economy from university professors to NASA engineers, organizational leadership roles to government elected officials (Yang, 2017). A recent U.S. Census (2017) captured two key areas of socioeconomic growth for Hmong Americans: 27\% of Hmong were college graduates compared to $30.6 \%$ of the U.S. population and $66.5 \%$ of Hmong were employed, which exceeded the entire U.S. population at 58.3\%. In addition, a growing number of Hmong women have become college educated and primary household income earners, transforming their traditional and primary roles as housewives in their families (Lee, 1997; Lor, 2013; Nguyen et al., 2011; Thao, 2020). Education rates among Hmong immigrants more than doubled between 1990 to 2000 (e.g., from $1 \%$ of Hmong age 25 or older having obtained a bachelor's degree to $3 \%$ respectively) (U.S. Census, 1990; U.S. Census 2000).

\section{Hmong Cultural Traditions}

Hmong customs, values, beliefs, and ideologies align around the extended family or a clan system (Lee \& Yuen, 2008). Traditionally, members of the collective Hmong community refer to each other as "ib tsoom kwv tij neej tsa" (i.e., the literal meaning is a group of Hmong relatives connected through marriage or a collective Hmong family) (Lee \& Yuen, 2008). The concept of extended family or clan is an influential social construct that results in Hmong from all walks of life operating as a collective group. This collective group identity also includes non-blood relatives and kin (Lee \& Yuen, 2008). This relational system is recognized via one's surname and clan representation. Those with similar surnames are believed to stem from the same lineage despite belonging to different biological family units, thus those with similar last names are forbidden to marry one another. Clan loyalty is implied (Lebar, 1964; Mottin, 1980). The collective nature of Hmong culture therefore implies that all Hmong are interconnected and essentially "Hmong relatives." This keeps the relational ties intact by reinforcing and acknowledging each other as kwv tij neej tsa (pronounced ku tee ning ja). Kwv tij literally means young brother-older brother and commonly refers to the husband's side of the family. 


\section{Asian Social Work Journal (ASWJ), Volume 6, Issue 5, (page 11 - 20), 2021 \\ DOI: https://doi.org/10.47405/aswj.v6i5.182}

Neej tsa refers to the wife's side of the family. The term kwv tij neej tsa refers to the union of two clans that is established through marriage and implies interconnected relationships of family ties.

Kwv tij neej tsa results in a collective bond that exists between Hmong families, which helps the community-at-large create social, economic, psychological, and political support systems amongst each other (Lee \& Yuen, 2008; Lee, 2010). When an individual or a family is faced with strife and/or celebrates life milestones, the community will offer support in the form of lub siab pab (i.e., literal meaning is: "help from the heart") demonstrated through altruistic acts such as monetary gifts and/or labor assistance (Lee \& Chang, 2012).

Recognizing Hmong social structures and its complexities can help social workers understand the experiences of Hmong clients. The cultural bond creates interconnections among Hmong families and communities, both locally, nationally, and internationally, across time and over many generations. Regardless of one's locale and country of residence, every Hmong person is perceived as " $k w v$ tij neej tsa" (Lee, 2020; Quincy, 2000; Mottin, 1980). This connects Hmong to one another when lineal linkage needs to be traced, embodies ethnic solidarity, and creates social order or a system on how to address one another. This collective identity allows members of the Hmong community to "muaj lub meej mom" (pronounced mua lou ming mo) or "to have dignity" (Lee \& Lee, 2015). Lub meej mom refers to a sense of personhood and identity, the connections to family and community upholds one's reputation as a member of the collective group, and contributes to one's personal and professional stature within the community. Lub meej mom allows one to demonstrate influence in order to effect outcomes for one's collective group locally, nationally, and globally.

With the Hmong family concept in mind, mainstream professionals are asked to develop an awareness and fluency in working with Hmong clients in the context of kwv tij neej tsa. This concept serves as a primary source of identity for many Hmong individuals and their family or kwv tij neej tsa and should be considered as a resource when engaging in problem solving with the client. Often, if the client's concern is not resolved timely through consultation with kwv tij neej tsa, or a decision from mainstream providers conflict with that of the kwv tij neej tsa, those within the helping profession such as social workers, nurses, and doctors can unknowingly exacerbate and prolong relational distress for the affected Hmong client, their family, and extended families (Her-Xiong \& Schroepfer, 2018; Lee \& Yuen, 2008).

Furthermore, if the social worker is Hmong, the social worker must acknowledge the inner workings of the kwv tij neej tsa construct. Any deviation from the construct can easily cause the client along with his/hers extended families and the Hmong community to label the social worker as a "bad social worker." The negative label is often extended to the social worker's personal family or clan due to the collective nature of the culture. In turn, when the social worker wishes to further engage clients from Hmong community, the request can be passively rejected or not fulfilled. The Hmong social worker may be essentially ostracized from the kwv tij neej tsa system due to perceived disrespect or ignorance of Hmong cultural values and beliefs surrounding the importance of kwv tij neej tsa.

\section{Culture and Oppression}

Cultural competency (Campinha-Bacote, 2019) is a prominent concept in the social work profession. Cultural competency promotes knowledge acquisition of differences and ease in working with those differences in practice. More recently, cultural humility (Foronda et al., 2016) has risen as a critique to the working principles of cultural competency by suggesting that competency not only requires knowledge acquisition and behavioral change, but also a cognitive component whereby the social worker acknowledges positions of power and accepts one's lack of knowledge of the client's culture, thus taking a position of humility rather than of mastery. One critical analysis of cultural humility suggests that neither political correctness nor semantic appeal gives cultural humility a utilitarian edge over cultural competence, although many healthcare practitioners and social workers want to see cultural competence replaced with cultural humility (Danso, 2018). We suggest that social workers use the anti-oppressive practice (AOP) framework, which utilizes both cultural competency and cultural humility. AOP asks the social worker to not only possess a working knowledge about the cultural 


\section{Asian Social Work Journal (ASWJ), Volume 6, Issue 5, (page 11 - 20), 2021 \\ DOI: https://doi.org/10.47405/aswj.v6i5.182}

group (e.g., cultural competence) but also to acknowledge and refrain from certain practice behaviors that may perpetuate oppressive practices upon a client (to be humble about one's lack of knowledge/acknowledge the potential of engaging in harmful behaviors). An example is, the social worker must refrain from needing to feel competent in a situation that is new to them which may result in the social worker imposing inaccurate or even harmful practices, and humbly acknowledge that they may not know very much about the situation at hand- deferring to the client as the expert on their own experience. This framework supports the changing social work education landscape that is highlighted in the current and forthcoming CSWE EPAS.

The challenges experienced by Hmong immigrants in America have often been attributed to clashes in cultural values and beliefs (e.g., traditional versus mainstream) (Ngo, 2008). Early research emphasized that cultural differences such as a desire for large families, early marriages, and preference for animistic practices in the Hmong community were viewed as impediments that bore significant responsibility in their maladjustments and high involvement in social service system in the U.S. (McInnis, 1991; Westermeyer \& Nugent, 1994). This singular spotlight on culture blames Hmong culture for systemic inequities experienced by Hmong Americans and absolves American institutions of oppressive and discriminatory values, practices, and policies (DePouw, 2012; DePouw, 2018). By situating Hmong culture as the problem, Hmong culture is continually compared to the mainstream American culture and assessed to be deficient (DePouw, 2012). Therefore, strengths and assets of Hmong culture are bounded to and overshadowed by this negative and sweeping assessment, which in turn can lead to the internalization of destructive representations of Hmong people (DePouw, 2012).

Experiences of early Hmong refugees in the U.S. have underscored negative encounters with American institutions and society. For instance, institutional contact with hospitals and the welfare system resulted in increased psychiatric symptoms (e.g., depression, somatization) among Hmong men (Westermeyer et al., 1984). In another study it was found that Hmong postpartum cultural practices were described as helpful for Hmong women's post birth (e.g., 30-day rest) and their anxiety stemmed from living in a different culture and raising their children with limited means (Stewart \& Jambunathan, 1996). Yet, the values and practices of American systems and culture have rarely been examined for their role in the ongoing disparities and inequities experienced by the Hmong American community. By drawing on an anti-oppressive framework, social workers can avoid further marginalization of Hmong culture and critically examine the various oppressive values and practices embedded within our current social welfare system to more effectively support Hmong Americans.

\section{Anti-0ppressive Practice, Empowerment and Strength-based Approaches}

Anti-oppressive practice (AOP) counters the tendency for social workers to reenact oppression that is structured in social welfare systems and services (Daniel, 2008; Wilson \& Beresford, 2000). Wilson and Beresford (2000) state that social workers shall conduct a critical analysis of theirs and their clients' positionality in social hierarchy and power, allowing for the analysis to shape social work activities and interventions towards the direction of inclusion and empowerment. The AntiOppressive Practice model links the social justice mission of the social work profession with direct practice with individuals, families, and small groups (Dominelli \& Campling, 2002). It is consistent with the United Nations' (1948) Universal Declaration on Human Rights which honors the rights of humans in all realms of life. Dominelli and Campling (2002) state that the goal of AOP is to foster clients to fully participate in society regardless of oppressive ideologies that justify exclusion, discrimination, and violence. In doing so, AOP contributes to macro-level changes by incrementally replacing oppressive ideologies with alternatives based on equality and acceptance. AOP practitioners recognize mechanisms of social injustice that operate in society, largely the admission and recognition of racism, ableism, xenophobia, ageism, homophobia etc. on the lives of clients. Approaches to translating AOP in behavioral health and social services have called upon strategies of empowerment, education, alliance building, intentional use of language, alternative healing and problem-solving methods, advocacy, and reflexivity (Corneau \& Stergiopoulos, 2012). 
Empowerment theory is a practice model which contextualizes human problems in a sociopolitical context that is oppressive to those most marginalized in society (Kam, 2020). Kam states that social work has been recognized as an empowering profession. Kam (2020) further states that the International Federal of Social Workers (IFSW), the International Association Schools of Social Work (IASSW, 2014), and the Council on Social Work Education (CSWE, 2020) support the notion that social work is a practice-based profession and academic discipline that promotes social change and development, social cohesion, and the empowerment and liberation of people. The empowerment approach continues to serve as a core concept in social work education, training, and related practices with clients. Social workers work collaboratively with people, both individually and collectively from many diverse backgrounds and needs, to achieve goals such as increasing personal, social, educational, and political power over their lives (Heffernan et al., 1997; Sheafer et al., 1997). Zastrow (1995) summarized empowerment as the mechanisms of: (1) helping clients define needs and clarify personal goals, (2) providing clients with education and resources, (3) helping clients gain clarity and an ability to change, (4) focusing on and enhancing client identity, (5) encouraging the client to develop a sense of autonomy, (6) helping clients develop social support systems, (7) helping clients find a balance to work and maintenance of personal relationships, (8) commencing the practitioner-client relationship with equality, and lastly (9) promoting assertiveness in clients.

Another dominant theory in social work practice with individuals, families, groups, and community is the strength-based approach (Saleebey, 1992; Oliver \& Grant, 2015). The strength-based approach focuses on clients' self-determination, helps clients build on their existing strengths which allows clients to be resourceful and resilient when faced with adversity. The strengths-based approach allows clients to take the lead in positioning themselves for more favorable outcomes (Oliver \& Grant, 2015).

\section{Application of AOP, Empowerment and Strength-based Approaches with Hmong clients: Three Key Areas to Focus on when working with Hmong Clients}

\section{Historical Trauma and Compliance}

A Hmong client can nonchalantly verbalize a "yes" when the response could easily be interpreted as a "no, I heard you, but I will not follow through with your recommendations." Verbal disclosure made by a Hmong client can be recorded as service compliance, yet in subtle ways it means the client has no desire to follow through with the personal or family problem. This stems from historical oppressive practices in which if a layman were to say no to someone in authority, the punishment would be severe. Social workers must keep in mind the historical trauma experienced by war refugees. Trauma experienced by many Hmong during the Vietnam War era at the hands of government authority and militia, as well as post migration trauma such as discrimination and poverty, may result in feigned compliance. Many have witnessed deaths of loved ones, have survived severe physical and psychological mistreatment, and have lost homes and possessions due to noncompliance with the government. Hmong also experienced trauma after arriving to the U.S.in the form of violence and discrimination that stem from xenophobia and anti-immigrant sentiment. For individuals who have experienced this type of trauma, it is better to feign compliance in the moment rather than risk punishment. AOP acknowledges that historical trauma may impact the manner in which a client responds to the provider. The worker is to acknowledge this historical trauma and empower the client to share their concerns about the treatment. It is essential that the worker works to create a safe space for the client to disclose their concerns and mistrust of the worker. In using a strengths-based approach, the worker would acknowledge the client's practice of self-preservation, acknowledge the client's intellectual ability to question before complying, and leverage the support of trusted family members in the helping process. When a Hmong client trusts the worker, they are more likely to collaborate with the worker in the helping process. Therefore, the social worker must be fluent in these skills in order to maintain their relationship with the client, which will lead to compliance and collaboration with treatment and a more effective helping relationship. 


\section{Alliance Building}

In the beginning stages when a client is seeking help or has been identified as needing social services, the development of client-worker alliance is imperative. Social workers must continually cultivate this in the client-worker relationship in order to achieve a collaborative working relationship (Bedi et al., 2005; Brossart et al., 1998). Alliance refers to the quality of the relationship between client and the social worker. It includes a purposeful collaboration, and affective bond (mutual respect, trust, and understanding). When the social worker is Hmong, the social worker typically shares cultural courtesy first and discusses how the service relationship will take place. Cultural courtesy within Hmong culture may take place in the form of acknowledging the social worker's family or group identification "Hello, my name is, and my family/or group association is..." However, when the social worker is not Hmong there is no need to disclose one's family group identity other than one's employer or association. This honors kwv tij neej tsa and any power or hierarchical structures recognized by the family. An AOP practitioner would honor the client and their family's inherent selfpower and the decision-making structure that exists within the family, rather impose western institutional values upon the family. The non-Hmong social worker may also build an alliance with a decision-maker or liaison who is often a family member (e.g., such as an adult child) or someone whom the family trusts in the community. The social worker can gain entry into the family system via this decision maker or liaison. This allows the social worker to work with the decision-maker or liaison to channel expectations and offer suggestions to the client via a cyclical communication loop. In turn the decision-maker can be used as leverage when conflicts arise and/or with issues that needs to be remediated. By doing this, the social worker is then viewed as one who is respectful and acknowledges the inner workings of the Hmong culture.

When a social worker is aware of these cultural nuances, is willing to remain humble, empowers the family system to utilize culturally specific methods of decision making, the social worker is viewed as one who is "good and/or righteous in preserving Hmong customs and traditions." This helps the client to acknowledge that the social worker is trying to resolve the issue/problem in their best interests and cultural values can be proactively used to reach a solution. Kwv tij neej tsa can be integrated wherever necessary to strengthen the helping relationship as the process is viewed much more effectively and trustworthy, particularly around issues of behavioral and mental health, domestic violence, child maltreatment, end of life care, and family relationships (Vang \& Bogenschutz, 2013).

\section{Cohort Assessment}

The year 2021 marks the $46^{\text {th }}$ anniversary of the beginning of Hmong immigration to the U.S. Due to the recent nature of immigration, differences in acculturation levels can still be detected between generations because first generation (first cohort) Hmong immigrants often came to the United States with little to no education, while later generations of Hmong (second cohort) either came as children, or were born in the U.S. Social workers must be able to assess the acculturation level of their client. A cohort assessment of Hmong clients may be divided into two generational cohorts: (1) those who are $\geq$ 50 years old and (2) clients who are $\leq 50$ years old.

A majority of Hmong in the first cohort are political refugees who came to the U.S. with language and cultural barriers (Hamilton-Merritt, 1993; Yang, 2017). Some may have children or grandchildren that belong to the second cohort. The cohort assessment of Hmong clients aged 50+ years must include the client's history that occurred in four phases: (1) life conditions while living in Laos, (2) migration out of Laos, (3) life in Thai refugee camps, along with (4) strengths and challenges of post-resettlement in the U.S. More importantly, their accumulative stressors that stem from unaddressed and unresolved psychiatric issues (i.e., loss of social status, traumatic loss of loved ones), chronic health conditions (i.e., somatic pain), faith-based background and conversion, the extent of family and clan relationships, and how they experience their life in the U.S. This cohort may struggle with poverty, language and cultural barriers, and lack of knowledge about systems, which greatly impacts their ability to navigate social service systems, and their ability to ask for what they need. Their focus may be on survival and tangible resources such as income, housing, and food assistance. Mental health may be foreign to them because western mental health constructs were not prevalent in their home country. 


\section{Asian Social Work Journal (ASWJ), Volume 6, Issue 5, (page 11 - 20), 2021 \\ DOI: https://doi.org/10.47405/aswj.v6i5.182}

In addition, this cohort may perceive government as authoritative and fear outsider intrusion on their private lives. AOP suggests that social workers be mindful of their inherent power in the relationship, engage in responsible use of power, provide education of systems, and collaborate with the client in the helping process. Strengths based approach asks social workers to explicitly identify clients' assets and resources, relationships and supports that are inherent to their culture, and the ability to utilize wholistic health practices among others. Social workers are asked to listen to the client and recognize the needs that they are seeking, in turn, empowering the client to express their needs with the social worker.

The second cohort (i.e., $\leq 50$ years old) consists mainly of those who came to the U.S. as children (i.e., $0-5$ years old), were born in the U.S., and the last major wave of refugees that occurred after the closure of the Wat Tham Krabok (the last Hmong refugee camp in Thailand) in 2004 (McGrew, 2019). The vast majority of Hmong in the second cohort are English literate. Some are likely to have parents who lack U.S. educational fluency, yet they have become model members in the Hmong community due to their pursuits of higher education. Similarly, the cohort assessment with members from this group can be focused on how the client perceives their Hmong identity and its relevance to their lived experience. This element is important, especially as some may be grappling with identity formation in the face of biculturalism. Many may integrate useful parts of traditional Hmong culture over another and/or reject parts of Hmong traditional culture that do not serve their lived experience within mainstream American culture. This dichotomy can cause them to develop internal conflict that may require further processing and support. Some may relearn and immerse themselves in Hmong cultural values and traditions passed down from their parents, while others may reject the Hmong culture altogether.

This second cohort is also known to be more agile and adaptable to mainstream culture. For those who struggle with their bicultural identity, social workers can help the client explore and determine how they perceive and understand their bicultural identities. A discussion about how the client navigates both cultures by switching between both cultures according to context (code switching), is often necessary due to having one foot in each culture. Varying cultural values create role conflict for bicultural individuals including individualism/collectivism, interdependence/independence, high context communication/low context communication among others. Finally, this cohort may be more aware of the realities of racism and other forms of oppression in the U.S., which can cause harm to their psychological well-being. It is critical for social workers to not only participate in the care and treatment of Hmong clients, but to also participate at various levels to reform and call out social injustices (e.g. join campaigns to end racism and violence against Asians and Asian Americans).

Using AOP, social workers are asked to refrain from making assumptions about the client's abilities based on their English language fluency or time in the U.S. as there may be variations in acculturation status despite language and cultural fluency. Social workers are asked to recognize the client's assets in terms of their abilities to navigate both cultures, and recognize their ability to be resilient in the face of bicultural stress. Clients should be empowered to choose for themselves in the face of conflicting cultural values and be given space to speak up for themselves. Because bicultural individuals often face conflicting expectations from both cultures, they must be empowered to ask their families for what they need as well as set boundaries and expectations with the social worker about what is working or not working.

\section{Conclusion}

The CSWE (2015) EPAS has laid groundwork in directing how to further culturally relevant social work practice by respecting the lived experiences of clients from underserved populations. Hmong and non-Hmong social workers can fulfill social workers' professional obligations by using the framework of anti-oppressive practice, empowerment, and strengths-based approaches with Hmong clients to better address the needs and problems of Hmong clients while honoring the clients' autonomy and culturally specific wisdom. It is our hope that this model and future evidence-based practice models (Drisko \& Grady, 2015) can eliminate all forms of oppression experienced by the Hmong community. 


\section{References}

Barney, G. L. (1990). The Meo of Xieng Khouang Province. Christianburg, Dalley Book Service.

Bedi, R. P., Davis, M. D., \& Arvay, M. J. (2005). The client's perspective on forming a counselling alliance and implications for research on counsellor training. Canadian Journal of Counselling, 39(2), 71-85.

Brossart, D. F., Wilson, V. L., Patton, M. J., Kivlighan, J. D. M. \& Multon, K. D. (1998). A time series model of the working alliance: A key process in short-term psychoanalytic counseling. Psychotherapy, 35(2), 197-205.

Campinha-Bacote, J. (2019). Cultural competenmility: A paradigm shift in the cultural

competence versus cultural humility debate Part I. Online Journal of Issues in Nursing, 24(1), 1-10.

Chen, M. S., Fang, D. F., Steward, S. L., Ly, M. Y., Lee, S., Dang, J. H.T. Nguyen, T. Maxwell, A. E., Bowlus, C. L., Bastani, R., \& Nguyen, T. T. (2013). Increasing Hepatitis B Screening for Hmong Adults: Results from a Randomized Controlled Community-Based Study, American Association for Cancer Research. DOI: 10.1158/1055-9965.EPI-12-1399.

Corneau, S., \& Stergiopoulos, V. (2012). More than being against it: Anti-racism and

anti-oppression in mental health services. Transcultural Psychiatry, 49(2), 261-282.

Council on Social Work Education (CSWE, 2020). Educational Policy and Accreditation Standards. https://cswe.org/getattachment/Accreditation/Standards-and-Policies/2015EPAS/2015EPASandGlossary.pdf.aspx.

Daniel, C. L. (2008). From liberal pluralism to critical multiculturalism: The need for a paradigm shift in multicultural education for social work practice in the United States. Journal of Progressive Human Services, 19(1), 19-38.

Danso, R. (2018). Cultural competence and cultural humility: A critical reflection on key cultural diversity concepts. Journal of Social Work 18(4), 410-430.

DePouw, Christin. (2012). When culture implies deficit: Placing race at the center of Hmong

American education. Race, Ethnicity and Education, 15(2), 223-239.

DePouw, C. (2018). Critical Race Theory and Hmong American Education. Hmong

Studies Journal, 19(1), 1-40.

Dewees, M. (2001). Building cultural competence for work with diverse families: Strategies from the privilege side, Journal of Ethnic \& Cultural Diversity in Social Work, 9(3/4), 33-51.

Dominelli, L, \& Campling, J. (2002). Anti-oppressive social work theory and practice. Macmillan International Higher Education.

Drisko, J. W., \& Grady, M. D. (2015). Evidence-based practice in social work: A contemporary perspective. Clinical Social Work Journal, 43, 274-282.

Fang, D. M., \& Steward, S. (2018). Social-cultural, traditional beliefs, and health system barriers of hepatitis B screening among Hmong Americans: A case study. Cancer, https://doi.org/10.1002/cncr.31096.

Foronda, C., Baptiste, D., Reinholdt, M. M., \& Ousman, K. (2016). Culturally humility: A concept analysis. Journal of Transcultural Nursing, 27(3), 210-217.

Hamilton-Merritt, J. (1993). Tragic Mountains: The Hmong, the Americans and the Secret War. Bloomington and Indianapolis: Indiana University Press.

Heffernan, J., Shuttlesworh, G., \& Ambrosino, R. (1997). Social work and social welfare: An introduction. West Publishing Company: Minneapolis/St. Paul.

Her-Xiong, Y. \& Schroepfer, T. (2018). Walking in two worlds: Hmong end of life beliefs \& rituals. Journal of Social Work in End-of-Life \& Palliative Care, 14(4), 291-314.

Hillmer, P. (2010). A People's History of the Hmong. St. Paul : Minnesota Historical Society Press.

Hmong Peace Task Force Committee (June, 2007). Laos, Hmong Hold Human Rights Rally To Protest Human Rights Violations, Ethnic Cleansing In Laos. Center for Public Policy Analysis. https://www.prlog.org/10019722-laos-hmong-hold-human-rights-rally-to-protest-human-rightsviolations-ethnic-cleansing-in-laos.html.

International Federation of Social Workers. Available at https://www.ifsw.org/.

Kam, P. W. (2020). Strengthening the empowerment approach in social work practice: An EPS model. Journal of Social Work, O(0). 1-24.

Lebar, F., et al., (1964). Ethnic groups of mainland Southeast Asia. New Haven: Human Relations Area Files Press. 
DOI: https://doi.org/10.47405/aswj.v6i5.182

Lee, G. Y. (2010). Culture and Customs of the Hmong. Santa Barbara, California: Greenwood.

Lee, G. Y. (2007). Diaspora and the Predicament of Origins: Interrogating Hmong Postcolonial History and Identity. Hmong Studies Journal, 8: 1-25.

Lee, M. N., (2015). Dreams of the Hmong Kingdom: The quest for legitimation in French Indochina, 1850-1960. University of Wisconsin Press.

Lee, S. C. (2020). Literature and history of Hmong Americans from preliterate to college aspirations and degree attainment among the 18 Clans. (In press. South China Normal University Press).

Lee, S. (1997). The road to college: Hmong American women's pursuit of higher education. Harvard Education Review, 67(4). 803-828. https://doi.org/10.17763/haer.67.4.0296u12hu7r65562

Lee, S. C., \& Lee, K. (2015). The Hmong Americans and their culture. In S. Lira, R. Amoeda, \& C. Pinhero (Ed.), Sharing Culture 2015 (pp. 425-431). Green Lines Institute for Sustainable Development.

Lee, S. C. \& Chang, J. (2012). Mental Health Status of the Hmong Americans in "2011: Three Decades Revisited". Journal of Social Work in Disability \& Rehabilitation, 11, 55-70.

Lee, S. C., \& Yuen, F. K. O. (2008). Hmong Americans' changing views and approaches toward disability: Shaman and other helpers. Journal of Social Work in Disability \& Rehabilitation, 2(3). 121-132. https://doi.org/10.1300/J198v02n02_08

Lor, P. (Spring 2013). A Hmong professional women's reflections and perspectives on the influences affecting the changing roles of Hmong women in America, Journal of Cultural Diversity, 20(1). 40-48.

McGrew, S. (December 19, 2019). Wausau Hmong community remember the closing of Wat Tham Krabok refugee camp. https://waow.com/2019/12/19/wausau-hmong-community-remembersthe-closing-of-wat-tham-krabok-refugee-camp/

McInnis, K. (1991). Practice forum: ethnic-sensitive work with Hmong refugee children. Child Welfare, 70(5), 571-580.

Mottin, J. (1980). History of the Hmong. Bangkok, Odeon Store.

Ngo, B. (2008). Beyond "Culture Clash" Understandings of Immigrant Experiences. Theory

into Practice, 47(1), 4-11.

Nguyen, T. H., Oosterhoff, P. \& White, J. (2011). Aspirations and realties of love, marriage and education among Hmong women. Culture, Health \& Sexuality. S201-215.

Oliver. C., \& Grant, C. (2015). Which strength-based practice? Reconciling strength-based practice and mandated authority in child protection work. Social Work, 60(2), 135-143.

PEW Research Center (2020). Hmong in the US fact sheet. https://www.pewresearch.org/socialtrends/fact-sheet/asian-americans-hmong-in-the-u-s/

Quincy, K. (2000). Harvesting Pa Chay's Wheat: The Hmong and America's secret war in Laos. Eastern Washington University Press.

Saleebey, D. (1992). The strengths perspective in social work practice. New York: Longman.

Sheafer, B. W., Horejsi, C. R., \& Horejsi, G. A. (1997). Techniques and guidelines for social work practice. $\left(4^{\text {th }} \mathrm{ed}\right)$. Allyn and Bacon.

Sommer, R. (2014). Hunted like animals. http:/www.sommerfilms.org/.

Stewart, S., \& Jambunathan, J. (1996). Hmong women and postpartum depression. Health Care

for Women International, 17(4), 319-330.

Thao, P. (2020). Gender theory and cultural considerations in understanding Hmong homicidesuicide. Hmong Studies Journal, 21. 1-24.

The International Association of Schools of Social Work. Available at https://www.iassw- aiets.org/.

United Nations (1948). Universal Declaration of Human Rights. https://www.un.org/en/aboutus/universal-declaration-of-human-rights.

U.S. Census Bureau. Hmong Census 2000 publication: Data and analysis. http://hmongstudies.org/2000HmongCensusPublication.pdf.

U.S. Census Bureau. We the Americans: Asians (1990). https://www.census.gov/prod/cen1990/wepeople/we-3.pdf.

U.S. Census Bureau. 2017 American Community Survey 1-Year Estimates. https://www.hmongstudiesjournal.org/uploads/4/5/8/7/4587788/hmongca_acs_17_1yr.pdf.

Vang, C., Sun, F., \& Sangalang, C., (2020). Mental health among the Hmong population in the U.S.: A systematic review of the influence of cultural and social factors. Journal of Social Work, $O(0) .1-20$. 
DOI: https://doi.org/10.47405/aswj.v6i5.182

Vang, P. D., \& Bogenschutz, M. (2013). Hmong women, marital factors and mental health status. Journal of Social Work, 13(2), 164-183.

Westermeyer, J., Bouafuely, M., \& Vang, T. F. (1984). Hmong refugees in Minnesota: Sex roles and mental health. Medical Anthropology, 8(4), 229-245.

Westermeyer, J., \& Nugent, S. (1994). Religiosity and psychosocial adjustment among 100

Hmong refugees. Asian American and Pacific Islander Journal of Health, 2(2), 133-145.

Wilson, A., \& Beresford, P. (2000). Anti-oppressive practice: Emancipation or appreciation. British Journal of Social Work, 30, 553-573.

Yang, K. (2017). The making of Hmong America: Forty years after the secret war. Lexington Books.

Zastrow, C. (1995). The practice of social work. (5th edition). Brooks/Cole. 